\title{
Commercially available endoscopy facemasks to prevent aerosolizing spread of droplets during COVID-19 outbreak
}

We read with great interest the ESGE and ESGENA Position Statement [1] on gastrointestinal endoscopy and the COVID19 pandemic. We share the concerns listed in the suggested research agenda, particularly about enhancing procedural protection in the endoscopy unit to reduce risk of COVID-19 dissemination. We would like to bring attention to commercially available endoscopy masks that can be used to avoid aerosolizing spread of droplets during upper endoscopic procedures. These products seem to improve intra-procedure risk management and can serve as an alternative to a modified ventilation mask reported for this purpose by Marchese et al [2].

For many years, we have been using the Endoscopy Mask (VBM Medizintechnik GmbH, Sulz, Germany) to administer gas anesthesia (sevoflurane), mainly to pediatric patients [3]. Its cushion inflation valve easily adapts to the patient's face and it also has a connector in the inferior part of the mask for inhalational anesthetic drugs. This mask is available in different sizes (newborn, infant, child, and adult). There are two adult size endoscopy masks, with a $32-\mathrm{mm}$ soft silicon membrane port in the center of the mask, with a 5-mm or $10-\mathrm{mm}$ opening that can be enlarged, cutting the silicon membrane to accommodate the scope outer diameter ( $\mathbf{F i g . 1 a , ~}$ Fig.1b, - Fig. 1c, - Fig. 1d). The soft silicon port allows for easy back-and-forth movement of the scope and a tight enough grip to avoid aerosolizing spread of droplets.

There are also at least two other products, the Endoscopy Mask (DEAS, Italy) [3] and the Intersurgical Explorer Endoscopy Mask (Intersurgical Wokingham, RG41 2RZ, UK) [4] that have similar characteristics and have proven to be safe for upper endoscopy.

These are safe, inexpensive and reasonably available products, which should be used in different upper endoscopy
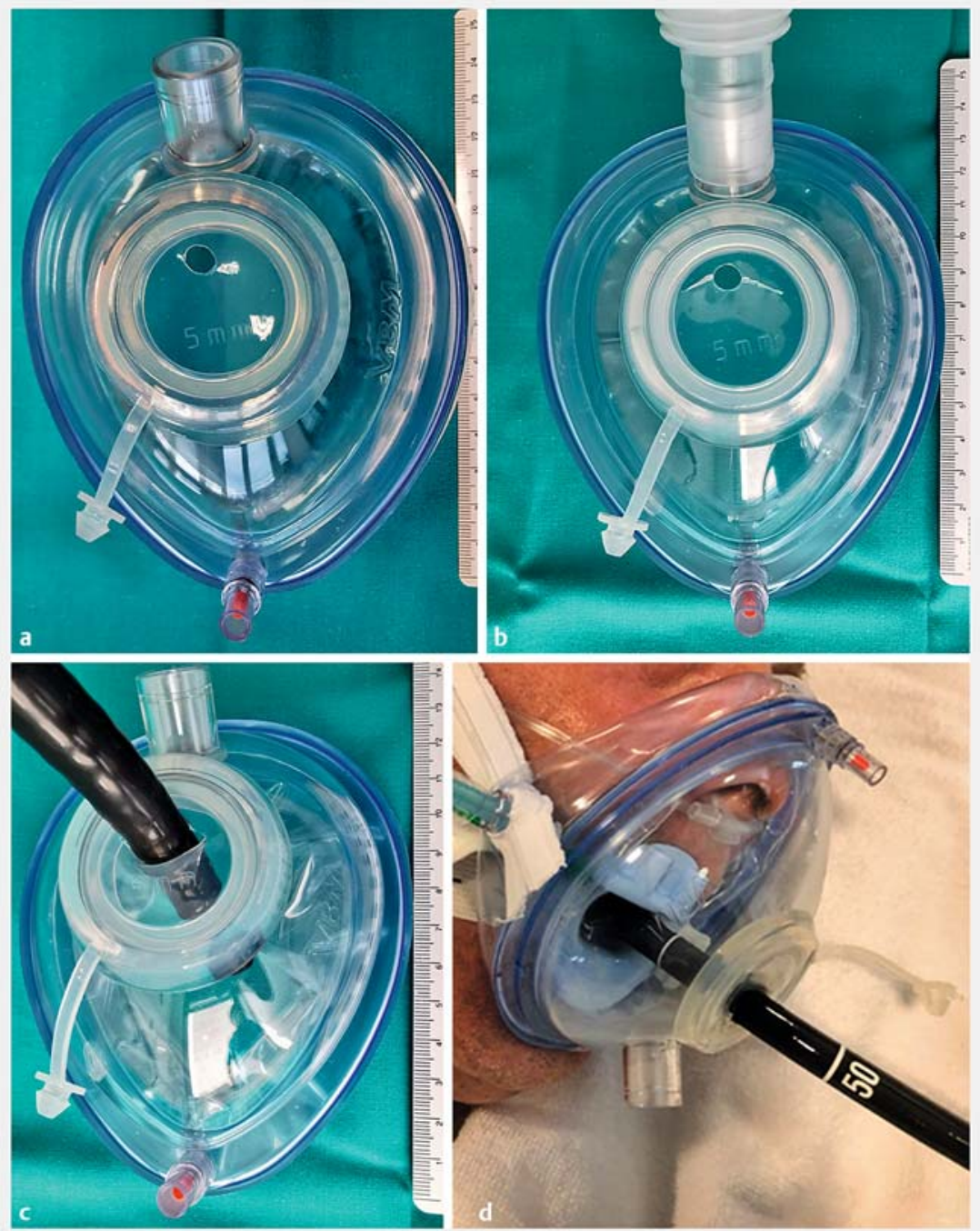

- Fig. 1 a An adult size Endoscopy Mask (VBM Medizintechnik GmbH, Sulz, Germany) with a soft silicone membrane port in the center of the mask and a 5-mm opening in the membrane. It has a cushion inflation valve for the face cushion and a connector in the inferior part of the mask for ventilation. $\mathbf{b}$ If necessary, the small opening can be cut slightly to accommodate the scope. c An adult size gastroscope GIF-HQ 190 (Olympus Europa Holding $\mathrm{GMBH}$, Hamburg, Germany) is comfortably passed through the previously widened opening in the silicone membrane. $\mathbf{d}$ Conventional upper endoscopy performed in a patient in left lateral position using the Endoscopy Mask.

procedures, especially during the COVID outbreak, creating an additional barrier to prevent health care professional infection through aerosolizing spread of droplets.

\section{Competing interests}

The authors declare that they have no conflict of interest. 
The authors

Alejandro Bojórquez, Francisco Javier Zozaya Larequi, Maria Teresa Betés, José Carlos Súbtil, Miguel Muñoz-Navas

Digestive Diseases Department, University Clinic of Navarre, Pamplona, Spain

Corresponding author

\section{Alejandro Bojórquez MD}

Digestive Diseases Department, University Clinic of Navarre, Ave. Pio XII, 36, 31008

Pamplona, Spain

Fax: +0034948296500

abojorquezg@gmail.com

\section{References}

[1] Gralnek IanM, Hassan C, Beilenhoff U et al. ESGE and ESGENA Position Statement on gastrointestinal endoscopy and the COVID-19 pandemic. Endoscopy 2020: doi:10.1055/a-1155-6229

[2] Marchese M, Capannolo A, Lombardi L et al. Use of a modified ventilation mask to avoid aerosolizing spread of droplets for short endoscopic procedures during coronavirus COVID-19 outbreak. Gastrointest Endosc 2020: doi:10.1016/j.gie.2020.03. 3853

[3] Torino A, Di Martino D, Fusco P et al. Hot topics in airway management during gastrointestinal endoscopy. J Gastrointest Dig Syst 2016; 6: 377. doi:10.4172/2161069X.1000377

[4] Potie A, Pregardien C, Pirotte T et al. Evaluation of the Explorer Endoscopy Mask ${ }^{\odot}$ for esogastroduodenoscopy in children: a retrospective studyof 173 cases. Ped Anesth 2016; 26: 649-654

\section{Bibliography}

DOI http://dx.doi.org/10.1055/a-1180-8355 Endoscopy International Open 2020; 08: E815E816

(c) Georg Thieme Verlag KC

Stuttgart · New York

eISSN 2196-9736

\section{(ㄷ)(1) $\Theta \Theta$}

